\title{
Arqueología y función social. Alguna teoría y unos cuantos ejemplos
}

Alberto López Mullorl

No hace mucho, un colega me describía el profundo malestar que había sentido al discutir durante horas con otros técnicos sobre ciertas cloacas aparecidas en una excavación urbana. La escena se había producido en plena calle, al borde de un sondeo, en uno de los barrios más populares de Barcelona. La gente los miraba intrigada, y quizá alguien se preguntó por qué cuatro hombres hechos y derechos haraganeaban en torno a unos objetos cotidianos, sin valor, y encima viejos.

Debo confesaros que yo también he sentido la misma incomodidad que mi amigo en alguna ocasión. El público no nos entiende, he llegado a pensar. Sin embargo, ipor qué habría de entendernos?

La práctica arqueológica, como sabéis, nació de la admiración por lo clásico, de la emoción del contacto con los testimonios materiales de un tiempo que la lejanía convirtió en edad de oro. La mera inquietud estética, con la llegada del arqueólogo profesional, se convirtió en afán clasificatorio y sistematizador. De ahí se deslizó irremediablemente hacia el lenguaje del arcano. Nuestra ciencia, reservada en principio a una élite económica, fue quedando en manos de otra élite, esta vez intelectual. El público, -insisto en llamarlo así, ya que de momento siempre se limita a pagar la entrada, y a aplaudirnos o a abuchearnos, sin comprender demasiado el argumento y carente de cualquier posibilidad de subir al escenario-; el público, digo, sigue mientras tanto prendado de la belleza de ciertos descubrimientos, o de las dificultades que arrostran algunos personajes casi heroizados, a quienes nadie espera identificar con el vecino de su rellano.

Ante una consideración popular de esta índole, a la que míster Spielberg y, más modestamente, los gacetilleros y redactores de enciclopedias han contribuído decisivamente, es lógico que sintamos vergüenza al tener que discutir sobre una cloaca del siglo pasado en plena vía pública.

Nadie cuestiona que la historia cumpla una función social, o por lo menos nadie debiera cuestionarlo. La especie humana tiene una curiosidad atávica hacia sus orígenes. Tal vez, porque el conocimiento del pasado y la vinculación, siquiera sentimental, a generaciones pretéritas con las que ya poco tiene que ver, le ayudan a comprender su cada día más dificil papel en el planeta.

La arqueología, por definición, como modo de investigación histórica, también contribuye a esta tarea y aun se señala en ella especialmente, pues, como se sabe, permite escribir la historia de quienes no tienen Historia. De este modo, nuestra contribución al progreso de las ciencias, debiera llenarnos de orgullo, y acallar todo remordimiento al pensar en ese público que no termina de entender los diálogos.

Con todo, son muchas las ocasiones en que seguimos sintiendo vergüenza, propia o ajena: al recorrer un parque arqueológico y escuchar los comentarios estupefactos de los visitantes, al abandonar un yacimiento después de excavado, convertido en paisaje lunar y dejado a su suerte, al escribir un libro de divulgación cuyo glosario ocupa una tercera parte del texto, y en las incontables ocasiones en que hay que mendigar subvenciones irrisorias para actuar en lugares solemnemente declarados Monumentos Nacionales o Patrimonio de la Humanidad.

Por eso, antes de hablar de función social es necesario, a mi entender, hablar de proyección social o, si se quiere, de su resultado: el reconocimiento 
social. No carece de mérito, en un país salido del analfabetismo hace poco más de dos generaciones, haber puesto en pié una práctica arqueológica generalizada y eficiente. Sin embargo, las consecuencias de nuestra labor no terminan de calar en la sociedad que las financia, a veces muy a su pesar.

En este panorama, de todos modos, nuestra responsabilidad no queda totalmente a salvo. La investigación arqueológica básica, realizada sustancialmente por los departamentos universitarios y centros similares, ha venido planteándose la resolución de problemas históricos o estrictamente arqueológicos, relacionados estos últimos con el estudio de los materiales, el método, etc. De este modo, sus logros, imprescindibles por otra parte, se hallan comúnmente alejados de una buena porción de los mortales, que sólo algunas veces reciben efímeras noticias a través de los medios de comunicación.

El público otra vez queda en ayunas, y sólo participará de la información al cabo de dos o tres décadas, destilada en los manuales escolares. De esta manera, cuando acierte a entender los diálogos, es muy posible que la obra haya sido retirada del cartel.

Acaso mis observaciones no sean atinadas, pues, junto a los centros docentes, otras instituciones se ocupan de la investigación aplicada, del salvamento del patrimonio en peligro. Es decir, realizan su labor en la calle, a la vista de todos. Las muy numerosas excavaciones de urgencia que se realizan en el país son un buen ejemplo de ello. Los poderes públicos las asumen como deber irremediable o suerte de maldición biblica. Es algo así como el obligado porcentaje de féminas en cargos de responsabilidad, vigente en alguna formación política, o la pequeña partida que toda obra pública debe dedicar al capítulo cultural, aunque no se sepa a ciencia cierta cuál va a ser su destino concreto.

Estas excavaciones, azote de propietarios remisos, tratan de evitarse mediante toda clase de triquiñuelas, y a decir verdad, no me extraña. Suelen consistir en la tarea de un grupo de mozalbetes, realizada a velocidad de vértigo, que deja a su paso desolación y sobre todo silencio. Un profundo silencio que sólo romperá el veredicto fatal de la autoridad constituída. Después, salvo en contadísimas excepciones, caerá el olvido sobre aquellos trabajos, que, en el mejor de los casos, contarán con una memoria archivada en una dependencia administrativa.

Existe, además, una tercera clase de excavacio- nes, realizadas por los que la legislación de mi Comunidad llama particulares. Es decir, los investigadores no adscritos orgánicamente a una institución científica homologada por nuestro gobierno autónomo. Una suerte de personajes abocados al estudio de ciertos temas que la legislación catalana considera prioritarios, entre los que, por ejemplo, no se encuentran el Paleolítico Superior, las villas romanas o las iglesias medievales. Unos decididos pioneros, en suma, que muy raramente obtendrán subvenciones, y de no hacerlo deberán demostrar documentalmente su solvencia económica para emprender excavaciones ?.

La contribución de esos particulares, hasta ahora sustancial y valiosa, se encuentra destinada a la extinción. Hablar de función social en este caso suena a sarcasmo, aunque en las últimas décadas los museos locales, los institutos comarcales, o simplemente los equipos de investigación que podríamos llamar liberales, hayan contribuido allí donde existen a que nuestra ciencia tenga un arraigo social profundo.

Por ahora resulta difícil acabar con el círculo vicioso que nos condena a la falta de proyección. Los resultados de las excavaciones rara vez llegan a conocerse, porque no se acaba de entender, o no acabamos de hacer entender a quien corresponda, que no sólo el objeto sino el destino de las Humanidades es el hombre.

A pesar de todo, me propongo demostrar que la arqueología, la historia en suma reconstruída a través de este método, también puede proporcionar calidad de vida. Una calidad intelectual, sin duda, que se aprecia tal vez subrepticiamente, tal vez a largo plazo; pero también una calidad material de aprovechamiento inmediato, si por ello entendemos la posibilidad de poder comprender lo que nos rodea y disfrutarlo plenamente.

Estas breves consideraciones pueden servir de introducción a una tarea que, junto con mi equipo, he intentado llevar a cabo durante los últimos diez años: la investigación arqueológica del patrimonio arquitectónico.

Vaya por delante mi plena conciencia de encontrarme en una situación de cierta anormalidad, en el sentido de no padecer las circunstancias de incuria o desidia hacia la arqueología normales en muchas instituciones del país, en las que, insisto, nuestra propia actitud tiene alguna responsabilidad. Afortunadamente, la Diputación de Barcelona cuenta con una larga tradición en la administración del patrimonio, que parte de la fundación en 1915 de 
los servicios de Investigaciones Arqueológicas -englobado actualmente en el Museo Arqueológico de Barcelona- y de Conservación de Monumentos, hoy de Patrimonio Arquitectónico Local.

Otro carácter anormal, también positivo a mi modo de ver, es la presencia en la plantilla del Servicio de arquitectos y aparejadores junto a arqueólogos y otros historiadores, todos ellos en pie de igualdad. Esta estructura interdisciplinar permite desarrollar por un mismo equipo orgánico todas las tareas que requiere la restauración de monumentos. Al tiempo, refiriéndonos al tema que hoy nos ocupa, permite percibir de una manera tangible la función social de nuestra labor; desde todos los puntos de vista.

Dado el carácter de la Diputación de ente administrativo inmediatamente superior a los municipios, y subsidiario de las necesidades de los mismos, nuestras actuaciones se realizan sin excepción a petición de los ayuntamientos, en lugares que son propiedad municipal, o dependen de la Administración Local a través de otro tipo de relaciones jurídicas, como cesiones o convenios. De esta manera, la actuación del Servicio no se determina por valoraciones estéticas, históricas o de otro tipo, sino que responde a las necesidades inmediatas de una comunidad.

De este primer enunciado ya se deduce que la actuación realizada revertirá inmediatamente en la sociedad, y que su fin último contribuirá a mejorar la calidad de vida en sus aspectos puramente materiales.

La mecánica de la restauración puede aportar otros datos. La metodología elaborada en el Servicio, a través de la reflexión conceptual y de la práctica cotidiana, considera en el monumento los valores arquitectónicos que son de rigor, pero también valores documentales 3. El propio monumento es depositario de informaciones que conviene desvelar para comprenderlo en toda su dimensión. En lo que a nosotros se refiere, el monumento es el yacimiento ${ }^{4}$.

Partiendo de esta base, resultaría temerario plantearse los criterios de restauración y mucho menos el proyecto sin realizar antes las investigaciones pertinentes. Esas investigaciones, en el campo arqueológico, conllevan el estudio exhaustivo del yacimiento. Es decir, no sólo se trata de realizar sondeos o análisis de otro tipo por debajo de la cota 0 , con el propósito de preservar las informaciones estratificadas en el subsuelo. Se trata tam- bién de estudiar cada uno de los elementos aéreos del yacimiento, para llegar a comprender el conjunto. La cota 0 de esta manera, permítaseme el simil, no está situada, por ejemplo, en el pavimento de la iglesia, sino que se coloca en la aguja del campanario.

Una investigación arqueológica realizada con este planteamiento incluye, lógicamente, la excavación extensiva de las naves del edificio, pero también abarca el análisis estratigráfico de paramentos y enlucidos o la excavación de las cubiertas. Siguiendo este procedimiento, es posible llegar a conclusiones que posibiliten la restitución de cada una de las etapas de la vida del monumento, tanto en planta como de manera volumétrica. Si a las informaciones proporcionadas por la arqueología se unen las procedentes de los estudios documentales, de la historia del arte, o del análisis constructivo y arquitectónico, realizados paralelamente, el conocimiento sobre el yacimiento y su evolución llega a unas cotas de exactitud muy razonables.

¿Cuál es la función social, quizá os preguntéis, de tal cúmulo de esfuerzos?. La primera y más inmediata es la de ver reflejados los resultados de la excavación en el proyecto arquitectónico. En este caso, tal vez no se deba hablar de función social, pero sí de reconocimiento social, del que tan faltos estamos. En nuestras excavaciones nadie se avergüenza de discutir durante horas sobre el recorrido o la pendiente de una cloaca histórica, porque seguramente de la discusión depende el correcto diseño de una futura cubierta.

En consecuencia, la excavación sirve también de manera directa para proporcionar unas calidades espaciales y ambientales acordes con el momento histórico que se desea evidenciar en la restauración. Tal vez no sea mucho, pero ante un panorama, a veces abrumador, de mixtificaciones y frivolidades arquitectónicas perpretadas en los monumentos, no deja de ser una función social la de poner al alcance de los ciudadanos las formas y los espacios históricos tal cuales eran. De este modo, el público, después de haber pagado la entrada y contemplar el escenario, podrá entender el decorado e identificarse con él.

El ámbito territorial de la Diputación y su campo preferente de acción, los municipios pequeños y escasos de medios, proporciona a nuestra tarea todavía otra posibilidad de incidencia social. Esta es mucho menos innovadora metodológicamente pero compendia las restantes. La excavación reconstruye la historia local, las más de las 
veces olvidada y en ocasiones imposible de escribir con otras fuentes. Conviene decir a este propósito que el ámbito cronológico de nuestros trabajos no excluye períodos recientes o teóricamente bien conocidos. Es tendenciosa la afirmación de que se puede historiar el feudalismo sin arqueología, como espero que demuestren en esta misma reunión voces más autorizadas que la mía. Lo mismo ocurre con las edades Moderna y Contemporánea, cuya documentación descuida sitemáticamente pequeños municipios y más aún pequeños edificios. Ignorar tales períodos en la excavación de un yacimiento equivale a destruir una información irreemplazable.

De todos modos, nuestra práctica habitual demuestra que el papel de la arqueología no concluye al finalizar la excavación. Debe continuar durante la obra de restauración, para abordar conjuntamente con las otras disciplinas lo que podemos denominar la presentación del monumento. Durante esta segunda etapa, la labor del arquitecto es decisiva, y el buen gusto -ese concepto tan dificilmente sistematizable- determinante. Sin embargo, la intervención en el monumento, cuya primera justificación es la de preservar sus valores históricos, aunque no desdeñe los puramente materiales, debe tener muy en cuenta las informaciones obtenidas mediante los estudios previos. Para ello nada mejor que la elaboración conjunta de los criterios de restauración por parte de arquitectos y arqueólogos, y la presencia de ambas clases de técnicos en el seguimiento de los trabajos.

Las obras suelen terminar con la inauguración oficial y casi siempre con una fiesta popular, en la que se celebra la vuelta del monumento, renovado, a la comunidad. Sin embargo, nuestra labor no ha terminado. Cumplida la evidente función social de poner a disposición del público un bien material, resta ayudar a enriquecer su significado. En nuestro caso, solemos valernos de una pequeña exposición permanente, instalada en el propio edificio, en que se muestran maquetas de su evolución, y se exponen los datos históricos, hasta ahora de forma literaria pero pronto también por procedimientos audio-visuales. Se editan además trípticos o folletos destinados a usuarios y visitantes. Por fin, tratamos de escribir la historia mediante publicaciones de divulgación y otras de carácter científico.

Es obvio que un proceso de esta índole presupone la existencia de un equipo estable, enriquecido con colaboraciones temporales, relativamente numeroso y dotado de medios suficientes, pero os asombraríais al comprobar el migrado por- centaje de inversión que ello supone, comparado con otros servicios de la Diputación, que puedan calificarse de normales y se hallan socialmente muy considerados, tales como el de Obras Públicas, o los más en boga de Parques Naturales o Medio Ambiente.

Lo dicho hasta aquí podría resultar un cúmulo de asertos más o menos teóricos, si no se ilustrase con algunos ejemplos. Por ello, me apresuraré a ponerlos. Me gustaría empezar por el más chocante, considerando que aquí nos ocupa la arqueología medieval y que hasta ahora me he referido al patrimonio edificado. Con todo, no me resisto a reflexionar sobre un modesto exponente de la arqueología urbana, aunque sea de época antigua. Se trata del conjunto formado por el establecimiento ibérico y la villa romana de Darró, situado en Vilanova i la Geltrú, en la costa mediterránea a cincuenta kilómetros al sur de Barcelona 5

El yacimiento se conoce desde el siglo pasado, fue objeto de algunas catas en los años cuarenta y de una primera excavación sistemática en los cincuenta, dirigida por A. Arribas. A principios de los setenta, la zona fue urbanizada y convertida en parcelas edificables situadas frente al paseo marítimo. La memoria histórica quedó pintorescamente preservada a través de un cipo con inscripción latina macarrónica, enclavado en una plazoleta ornada con exóticas palmeras. Acto seguido, se inició la edificación intensiva.

Afortunadamente, las crisis cíclicas de nuestro sistema económico, que tanto han hecho por el patrimonio, paralizaron la actividad constructora, y al reemprenderse tímidamente, ya en 1977, las ruinas ibéricas que ya se creían muertas y sobre todo enterradas, volvieron a aparecer escandalosamente. Como además del ciclo económico había empezado a cambiar el político, fue posible emprender una excavación de urgencia, primero a cargo de un grupo local, dotado de más entusiasmo que conocimiento, y después por parte del Museo Arqueológico de Barcelona, cuya dirección me fue encomendada. En 1983 nuestro Servicio se hizo cargo del yacimiento, con ánimo de proceder a su ordenación y restauración, mientras tanto el gracejo popular, que no es exclusivo de Andalucía, ya lo había bautizado como el solar de las momias.

Con tales antecedentes no está siendo fácil poner de relieve la función social de los trabajos en Darró. No obstante, me esforzaré en demostrarla. 
La primera operación realizada en el conjunto fue su delimitación. Teniendo en cuenta que los materiales de superficie abarcaban áreas urbanas muy extensas y otras rústicas de no menor entidad, fue necesario realizar una detenida prospección, que puso de relieve otros cuatro yacimientos secundarios, pero también hubo que abrir más de doscientas catas. Esta labor nos proporcionó un perímetro arqueológico perfectamente nítido, que permitió desafectar numerosas parcelas edificables, en las que, según nuestras indicaciones, el Ayuntamiento había suspendido la concesión de licencias.

He aquí una primera función social, quizá de menor cuantía pero de aplicación inmediata. También una proyección social interesante: la arqueología sirve para detener obras pero también para poder realizarlas con todas las garantías. Los inquilinos de los nuevos apartamentos, construídos en las zonas que se revelaron estériles, miran con otros ojos el solar de las momias, y sobre todo no temen haber pisado una venda.

Una vez resuelto el problema cuantitativo, se trataba de abordar el cualitativo. En consecuencia, el yacimiento, o mejor dicho su zona más afectada por un plan general miope, fue objeto de una excavación sistemática extensiva, complementada con sondeos en puntos significativos. De este modo pudimos saber que el poblado ibérico databa del siglo $V$ a.C., de sus muy estrechas relaciones con la Ibiza púnica hasta finales del siglo III a.C., de su remodelación a raíz de la conquista romana, y de la instalación de una típica villa de la costa de la Tarraconense, cuya última fase edilicia fue concluída hacia mediados del siglo $V$ de nuestra era. También comprobamos, por cierto, la roturación del terreno a finales del siglo XIV, y su utilización para el cultivo intensivo de la viña desde mediados del siglo XVII hasta finales del XIX.

Tales informaciones, obviamente útiles, unidas a la presencia de estructuras de mayor o menor porte a lo largo de los predios estudiados, nos permitieron trazar los límites de una zona de máximo interés arqueológico. Es decir, de aquellos sectores en los que la potencia del yacimiento excedía de los veinticinco centímetros. De esta manera, el Servicio pudo elaborar las directrices de una modificación de detalle del Plan General de Ordenación Urbana, que, aprobada por el Ayuntamiento, fue refrendada por las instancias competentes. Tras este paso, la arqueología había vuelto a contribuir a hacer ciudad.
En este momento, nos encontramos en la tercera etapa del proceso. Las ruinas, per se, deben ver ultimado su estudio exhaustivo, y ha de emprenderse la restauración. Por ahora, el proyecto se encuentra al inicio de su andadura, y sólo se conocen sus objetivos. No obstante, si lo permite la evolución de los distintos ciclos que antes mencionaba, esperamos convertir Darró en un espacio público, visitable e inteligible, dotado de las anastilosis arquitectónicas que se estimen oportunas, y de una pequeña instalación monográfica que ilustre al visitante. Paralelamente, además de las publicaciones estrictamente científicas, ya ha visto la luz un librito de divulgación sobre el conjunto, se han pronunciado conferencias y lecciones, ante distintos auditorios de Vilanova o la comarca, y se trabaja en la confección de unidades didacticas escolares.

Vilanova también es un núcleo turístico, y Darró puede ser uno de sus capitales futuros. Por eso, el otro día, estando en la excavación, vimos venir hacia el yacimiento el trenecito de los turistas: esa caravana de jardineras tirada por un tractor disfrazado de locomotora. El tren en cuestión, en vez de dar la vuelta en el paseo marítimo, antes de llegar -como siempre hacía-, se internó en una calle que todavía cruza las ruinas, y por el altavoz se oyó una voz que explicaba a los viajeros: aquí se encuentran las ruinas del importante poblado iberoromano de Darró. ¿Habrá terminado por fín la maldición del solar de las momias?.

El segundo ejemplo se refiere a un conjunto mayoritariamente medieval. Se trata del monasterio de Sant Llorenç prop Bagà 6 . Este antiguo cenobio, aun cuando su topónimo indica que se halla cerca del pueblo de Bagà, lo cual es rigurosamente cierto, se encuentra a las afueras del casco urbano de Guardiola de Berguedà, un pequeño núcleo de población surgido en torno a una estación del ferrocarril minero desde finales del siglo XIX. Guardiola está a los pies del macizo del Cadí, en el Prepirineo, a ciento veinte kilómetros al noroeste de Barcelona.

El monasterio era conocido a través de la documentación desde finales del siglo IX, se sabía también la fecha de consagración de su iglesia, ocurrida en el 983, y que había sido víctima de un terremoto, muy probablemente el día de la Candelaria de 1428. Sin embargo, el conjunto que había llegado a nosotros en 1982, al iniciarse la intervención del Servicio, comprendía un templo poco agraciado, de estilo más bien indefinido, aunque de claro origen medieval. A su lado se había edificado un seminario de verano en los años sesenta, aprove- 
chando los restos de una construcción anterior.

Debe decirse que las obras se iniciaron un año antes de que el Servicio contase con el actual departamento de Investigación Arqueológica. Ello facilitó que el arquitecto colaborador emprendiese por su cuenta ciertas exploraciones en el sótano de la iglesia, hasta entonces casi repleto de tierras, o en algunos sectores del entorno.

En este punto me permitiréis un breve excursus, pues conviene advertir que actuaciones de esta índole, que en el yacimiento cesaron inmediatamente ante los nuevos planteamientos metodológicos aplicados por nuestra institución, continúan siendo práctica habitual en algunos lugares, en la creencia de que el técnico preparado y contratado para el diseño también debe ocuparse de minucias complementarias, tales como la documentación histórica del monumento, al tiempo que, pongamos por caso, levanta los planos. Quizá tal modo de proceder se deba a que, como observaba al principio, la proyección de nuestra ciencia es escasa. Sin embargo, más bien me inclino a creer que antes he sido optimista al considerar alfabetizado el país hace dos generaciones.

Volviendo a nuestro monasterio. Su aspecto antes de las obras era más bien siniestro. Subdividido en dos pisos, carente de iluminación interior, y extremadamente desproporcionado, con altísimos muros en una fábrica bastante corta. Los especialistas lo tildaban de románico, título honrosísimo en la historia del arte catalán, que no acababa de merecer. Su uso litúrgico era sólo esporádico, en la fiesta del santo patrón, y la iniciativa del párroco lo había completado con audiciones de música clásica en las noches veraniegas.

Nuestra actuación en Sant Llorenç consistió en la excavación extensiva del interior del templo y de su entorno inmediato, incluídos los bajos del seminario de verano, actualmente casa de colonias, en cuyo ámbito se atisbaban algunas estructuras que se habían identificado como dependencias monacales. También se realizó un detenido estudio de la fábrica de estas construcciones, excepción hecha del campanario y de las cubiertas del templo, restaurados en 1983.

La excavción, realizada casi ininterrumpidamente desde 1984 a 1988, puso de manifiesto que la iglesia primitiva, mejor denominarla basilica atendiendo a su morfología, se había edificado a finales del siglo $X$, coincidiendo con el acta de consagración, y consistía en un edificio rectangular, de 33 por 18 metros, dividido en tres naves y dotado de seis puertas, tres al sur, dos al norte y otra en la fachada de levante. El presbiterio se hallaba a occidente.

La fábrica fue enriquecida hacia el segundo cuarto del siglo XI con dos absidiolas al oeste de las naves colaterales. A mediados del siglo XII se edificó una espléndida tribuna que ocupaba la mitad occidental de la nave mayor, complementada con una cabecera cuadrangular, situada entre las dos absidiolas del siglo anterior. Lo que conocemos del monasterio indica que sus dependencias actuales se erigieron casi al mismo tiempo que la basilica, compartiendo, al poco, pórtico con la misma. Algo después de haberse erigido la tribuna, se añadió al monasterio un austero claustro de arcos lisos, que complementaba a otro anterior seguramente situado a pocos metros.

Todo el conjunto quedó gravemente afectado por el terremoto del siglo $\mathrm{XV}$, pero malvivió sin cambios hasta el segundo cuarto del XVII. Entonces, sólo se aprovechó la mitad de poniente del templo, rodeándolo completamente de dependencias, algunas de nueva planta, otras reutilizando la mitad de la basilica que ya no tenía uso litúrgico. Tales dependencias fueron soterradas hacia 1725 , quedando exentas la iglesia y el monasterio, que para entonces ya sólo era priorato. A principios del siglo XIX, se reconstruyó la nave norte del templo, siempre únicamente en su mitad de poniente, y el conjunto adquirió los grandes rasgos de la apariencia que ha llegado a nosotros.

Tan apretada explicación quiere evidenciar que, a no ser por la excavación, jamás se hubiera podido interpretar la evolución de este yacimiento, aun cuando, todo hay que decirlo, ciertos historiadores del arte discrepan de nosotros, al considerar que las partes que hemos hallado en ruinas, al no estar completas, jamás llegaron a construirse. Curiosa deducción ante un conjunto arqueológico.

La excavación, además de este resultado evidente, tuvo otros que no lo son menos, a la vista de la restauración posterior. Ahora, el visitante, puede deambular por un espacio que, al menos parcialmente, restituye el ambiente en que se movió la comunidad benedictina. Puede también admirar uno de los escasísimos ejemplos de tribuna monacal románica que se conservan -en nuestro país es el único-, y andando el tiempo, aquí tampoco hemos concluído nuestra labor, podrá pasearse por un parque arqueológico de las épocas medieval o moderna, complementado por una pequeña instalación 
museística. El pueblo de Guardiola, situado en la ruta de paso hacia las muy frecuentadas pistas de esquí de la Cerdanya y Andorra, contará con un atractivo turístico de primer orden. Además, su historia local habrá dado un salto de mil años, aunque, eso sí, el monasterio no es exactamente románico, lo cual constituye un cierto desdoro.

Conviene añadir que, en un futuro próximo, Sant Llorenç, junto con otros edificios prerrománicos y románicos restaurados por el Servicio en la comarca -uno de los cuales os describiré seguidamente-, formará parte de una ruta de turismo cultural promocionada por la Diputación, cuya máxima atracción serán el arte y la arqueología medievales.

Sólo voy a cansaros con otro ejemplo. Corresponde a una actuación acabada, en la que se han querido destacar por encima de todo los valores históricos. Se trata de la iglesia de Sant Vicenç de Rus, en Castellar de N'Hug 7, un pueblecito de montaña cercano al límite de la provincia de Barcelona con la de Lleida, situado en las mismas estribaciones pirenaicas que Guardiola de Berguedà, a unos ciento cuarenta kilómetros de la capital. Castellar acoge un gran número de turistas interiores y algunos foráneos, que llegan atraídos por el tipismo, los embutidos y los certámenes de perros pastores.

El edificio se encontraba abandonado desde la guerra civil de 1936-1939, y el Ayuntamiento del pueblo solicitó su restauración en 1982 para convertirlo en equipamiento cultural. No obstante, debéis saber que la iglesia se encuentra al pie de la carretera a unos 8 kilómetros del núcleo urbano, en un paraje montañoso cubierto de bosques, cercano al nacimiento del río Llobregat. Estas circunstancias hacían abrigar dudas sobre la utilidad de tan alejado equipamiento.

De cualquier modo, se tomó en cuenta la petición, y el Servicio comenzó a proyectar una especie de casa de cultura. En aquellos tiempos, las investigaciones previas eran más bien superficiales. Sin embargo, el hallazgo de unos magníficos frescos de los siglos XII y XIV al reconocer los paramentos interiores del templo, ocurrido en 1983 , dio pie para replantearse el sentido de los trabajos.

Así, las pinturas pusieron fin al proyecto de casa de cultura, y antes de plantearse cualquier otro, empezó el estudio del edificio. Por nuestra parte, recién creado el departamento de Investigación Arqueológica, desarrollamos campañas en 1983,
1985 y 1986. Esta actuación permitió el descubrimiento de las ruinas de un templo anterior al actual, citado en los textos desde mediados del siglo $X$. También nos dio ocasión de documentar al detalle el edificio del siglo XII, cuyos componentes esenciales habían llegado a nosotros sin grandes cambios. Igualmente se realizó el estudio detenido de las etapas moderna y contemporánea, y se pudo excavar una considerable extensión de la necrópolis medieval que rodeaba la iglesia.

Una vez concluídas las investigaciones paralelas de historia del arte y documental, ésta última sin grandes resultados ante la escasez de fuentes, se planteó el criterio de restauración. Teniendo en cuenta la situación del edificio, fuera del casco urbano, pero junto a una carretera bastante frecuentada, su relativo buen estado de conservación, el hecho de conocerse casi al detalle su evolución arquitectónica, y su carencia de actividades litúrgicas, se decidió darle el aspecto prístino de un templo del siglo XII, modificado parcialmente a principios del XIV, ya que las pinturas murales de esta época se conservaban in situ en una capilla lateral situada al sudeste del presbiterio.

En consecuencia, nos aprestamos a la restitución del aspecto de un templo rural románico típico, de los que se cuentan por millares en Cataluña, aunque muy pocos de ellos conserven su apariencia original. De este modo, empeñados en una presentación exclusivamente didáctica, justificada en este caso por la carencia de cualquier otro uso, se reconstruyó el pavimento con una especie de opus signinum que remedaba el suelo de tierra batida encontrado, pero facilitaba su mantenimiento; se rebocaron las paredes, a imitación del enlucido blanquecino de los primeros tiempos, y en el ábside se reprodujeron las pinturas del siglo XII, descubiertas al principio de la obra, y más tarde arrancadas e instaladas en el Museo Diocesano de Solsona. En la cubierta se colocó el entramado de losas que la excavación había revelado, y en el entorno se recuperó la topografía averiguada por los mismos medios.

Sería largo de contar el proceso de recuperación de mil y un detalles, debido a los estudios constructivos, de historia del arte y arqueológico, por eso lo mejor es observar algunas de las ilustraciones que presentamos. En ellas no falta la maqueta instalada en el edificio, donde se reflejaron aquellos pormenores que la inseguridad nos impidió colocar en el monumento.

Desde su inauguración Sant Vicenç de Rus 
cuenta con un servicio de guardia semipermanente, que facilita las visitas. También se editaron los trípticos y postales de rigor, que se distribuyen gratuitamente. Por fin, las conclusiones de todas las investigaciones han aparecido en diversos artículos y una monografía.

No quisiera terminar habiendo dado la impresión de que los ejemplos presentados resultan enteramente paradigmáticos. Ni siquiera si los he elegido acertadamente, y me temo que no los he expuesto con donaire. Me conformo con participaros que los miembros de mi equipo nos contentamos con que el público, ése que siempre paga la entrada, entienda y quizá aplauda nuestra puesta en escena.

\section{NOTAS}

2 Sobre tal situación, puede verse: "Debat". Revista d'Arqueología de Ponent. (Lleida), vol. 2. 1992, pp. 236252.

3 A. GONZALEZ: Recerca i disseny. El monument com a document històric i com a objecte arquitectònic viu. Servei de Catalogació i Conservació de Monuments de la Diputació de Barcelona. Barcelona, 1985. (Con versiones castellana e inglesa). Id., "A la recerca de la Restauració Objectíva". Memòria 1985-1989, Servei del Patrimoni Arquitectònic de la Diputació de Barcelona. Barcelona, 1990, pp. 7-12 (con versión castellana).

4 A. LOPEZ MULLOR: "Consideracions metodològiques sobre l'actuació del Servei de Catalogació i Conservació de Monuments en el camp de la recerca arqueològica". Memòria 1984, Servei de Catalogació i Conservació de Monuments de la Diputació de Barcelona. Barcelona, 1986, pp. 19-21, 158-160 (con versiones castellana e inglesa). Id.: "Set anys d'investigació arqueològica del patrimoni arquitectonic" Memòria 1985-1989, Servei del Patrimoni arquitectònic de la Diputació de Barcelona. Barcelona 1990, pp. I3-I8 (con versión castellana).

5 Entre la numerosa bibliografía generada por este yacimiento puede verse: A. ARRIBAS: "La primera campaña de excavaciones en el poblado ibérico y la "villa" romana de Adarró (Villanueva y Geltrú). Excavaciones de 1956". Boletín de la Biblioteca-Museo Víctor Balaguer. Vilanova i Geltrú, V época, IV, 1956, pp. 23-48. Id.: "El poblado ibérico y villa romana de Adarró (Villanueva y Geltrú)". Ampurias. Barcelona, vol. XXl, 1959, pp. 232239. A. LOPEZ MULLOR, A. FERRER: "Hallazgos anfóricos en el establecimiento ibérico y romano de Darró (Vilanova la Geltrú)". Informació Arqueològica. Barcelona, vol. 39, julio-diciembre 1982, pp. 82-89. Id.: "Darró o
Aderró o Adarró, Vilanova i la Geltrú". Les excavacions arqueològiques a Catalunya en els darrers anys. Barcelona, 1982, pp. 342-344. Id.: "Avance de los resultados de las excavaclones en el establecimiento ibérico y romano de Darró, Vilanova i la Geltrú, Barcelona (1979-198I)". Homenaje al prof. Martín Almagro Basch, III. Madrid, 1982, pp. 109-I19. A. LOPEZ MULLOR: "Una peculiar producción de cerámica de paredes finas en la Costa Catalana". Rivista di Studi Liguri. Bordighera, XLVI, 1980 (1983), pp. 33-40. Id.: "Establiment ibèric i romà de Darró". Memoria 1984, Servei de Catalogació i Conservació de Monuments de la Diputació de Barcelona. Barcelona, 1986, pp. 129-142; 198-203 (con versiones castellana e inglesa). A. LOPEZ MULLOR, J. FIERRO: "La época ibérica en Darró, Vilanova i la Geltrú, Barcelona. Evidencias e hipótesis proporcionadas por las últimas excavaciones (1984-1988)" . Homenaje al Prof. Eduardo Ripoll Perelló. Espacio, Tiempo y Forma, Madrid, serie II, I, 1988, pp. | |7- |4 |. Id.: "Darreres intervencions a l'assentament ibèric i la vil.la romana de Darró (vilanova i la Geltrú, Garraf)". Tribuna d'Arqueologia 1987-1988, Servei d'Arqueologia de la Generalitat de Catalunya. Barcelona, 1988, pp. 53-68. A. LOPEZ MULLOR: "Nota preliminar sobre la producción anfórica de Darró, Vilanova i la Geltrú (Barcelona)". Société Française d'Etude de la Céramique Antique en Gaule. Actes du Congres de Lezoux. Marsella, 1989, pp. 109-122. A. LOPEZ MULLOR, J.FIERRO: "La época romana en Darró (Vilanova i la Geltrú, Barcelona)". Espacio, Tiempo y Forma. Madrid, Serie I Prehistoria y Arqueología, 3, 1990, pp. 203-254. Id.: "Un conjunt ceràmic de l'època baix-republicana trobat a l'establiment ibèric de Darró, Vilanova i la Geltrú". Miscel.lània Penedesenca. Sant Sadurni d'Anoia, XV, 1991 (1992), pp. 137-196. A. LOPEZ MULLOR, X. FIERRO, A. CAIXAL, A. CASTELLANO: La primera Vilanova. L'establiment ibèric i la vil.la romana d'Arró, Darró o Adarró de Vilanova i la Geltrú. Síntesi dels resultats de les darreres recerques arqueològiques i històriques. Sant Sadurní d'Anoia, 1992. A. LOPEZ MULLOR, X. FIERRO: "Materials per a una classificació de la ceràmica ibèrica al torn produïda a Darró (Vilanova i la Geltrú)". Miscel.lània Penedesenca. Sant Sadurní d'Anoia, XVI, 1992 (1993), pp. 7-97.

6 Bibliografía esencial sobre nuestras investigaciones en el yacimiento. A. LOPEZ MULLOR: "Guardiola de Berguedà. Sant Llorenç prop Bagà". Catalunya Romànica XII. El Berguedà. Barcelona, 1985, pp. 298-303. Id.: "Monestir de Sant Llorenç prop Bagà. Resultat de les excavacions arqueològiques". Memoria 1984, Servei de Catalogació i Conservació de Monuments de la Diputació de Barcelona. Barcelona, 1986, pp. 88-98, 186-189. A. LOPEZ MULLOR, A. CAIXAL: "Monasterio de Sant Llorenç prop Bagà (Guardiola de Berguedà, Barcelona). Novedades Arqueológicas". II Congreso de Arqueología Medieval Española, III. Madrid, pp 1987, pp. 339-349. A. LOPEZ MULLOR: "Monestir de Sant Llorenç prop Bagà. Guardiola de 
Berguedà. Descripció del conjunt. Notícia històrica". Memòria 1985-1989, Servei del Patrimoni Arquitectònic de la Diputació de Barcelona. Barcelona, 1990, pp. 212 215, 219-220 (con versión castellana). A. LOPEZ MULLOR, A. CAIXAL: "Monestir de Sant Llorenç prop Bagà. Guardiola de Berguedà. Treballs d'arqueologia". Memoria 1985-1989, Servei del Patrimoni Arquitectònic de la Diputació de Barcelona. Barcelona, 1990, pp. 215-216, 220 (con versión castellana). A. LOPEZ MULLOR: "La excavación del monasterio de Sant Llorenç prop Bagà, campañas 1984-1989". Simposio Actuaciones en el patrimonio medieval y moderno (siglos X-XVIII), Servei del Patrimoni Arquitectónic de la Diputació de Barcelona. Barcelona, 1991, pp. 67-90. A. LOPEZ MULLOR, A. CAIXAL: "Resultados de las excavaciones realizadas en el monasterio de Sant Llorenç prop Bagà (Guardiola de Berguedà, Barcelona). campañas 1984-1987”. Actas del Congreso Intemacional de Historia de los Pirineos. Cervera, 1988, vol. II. Madrid, pp. 243-258.

7 Bibliografía esencial sobre las campañas realizadas en el yacimiento. A. LOPEZ MULLOR, M.J. SUREDA: "Església de Sant Vicenç de Rus. Situació geográfica. Notícia historica. La recerca arqueologica". Memòria 1983, Servei de Catalogació i Conservació de Monuments de la
Diputació de Barcelona. Barcelona, 1984, pp. 174-178, 268-270 (con versiones castellana e inglesa). A. LOPEZ MULLOR: "Castellar de N'Hug. Sant Vicenç de Rus". Catalunya Romànica XII. El Berguedà. Barcelona, 1985, pp. 179-185. A. LOPEZ MULLOR, A. CAIXAL: "La época medieval en la iglesia de Sant Vicenç de Rus, Castellar de N'Hug (Barcelona). Resultados de las excavaciones". II Congreso de Arqueología Medieval Española, III. Madrid, 1987, pp. 533-544. A. LOPEZ MULLOR (dir): Recerques històrico-arqueològiques al Berguedà (1983-1986). Església de Sant Vicenç de Rus, Esglesia de Santa Eulàlia de Gironella, Pont Vell de La Pobla de Lillet, Diputació de Barcelona, Servei del Patrimoni Arquitectònic, Quaderns Científics i Tècnics, I. Barcelona, 1989, pp. 8-I35. A. LOPEZ MULLOR: "Església de Sant Vicenç de Rus. Castellar de N'Hug. Notícia historica. Treballs d'Arqueologia". Memòria 1985-1989, Servei del Patrimoni Arquitectònic de la Diputació de Barcelona. Barcelona, 1990, pp. 199-202, 208 (con versión castellana). A. LOPEZ MULLOR, A. CAIXAL: "La evolución arquitectónica de la iglesla de Sant Vicenç de Rus (Castellar de N'Hug, Barcelona) durante el período medieval: resultados de las excavaciones". Espacio, Tiempo y Forma Madrid, Serie VIII Historia del Arte, 3, 1990, pp. 31-54. 

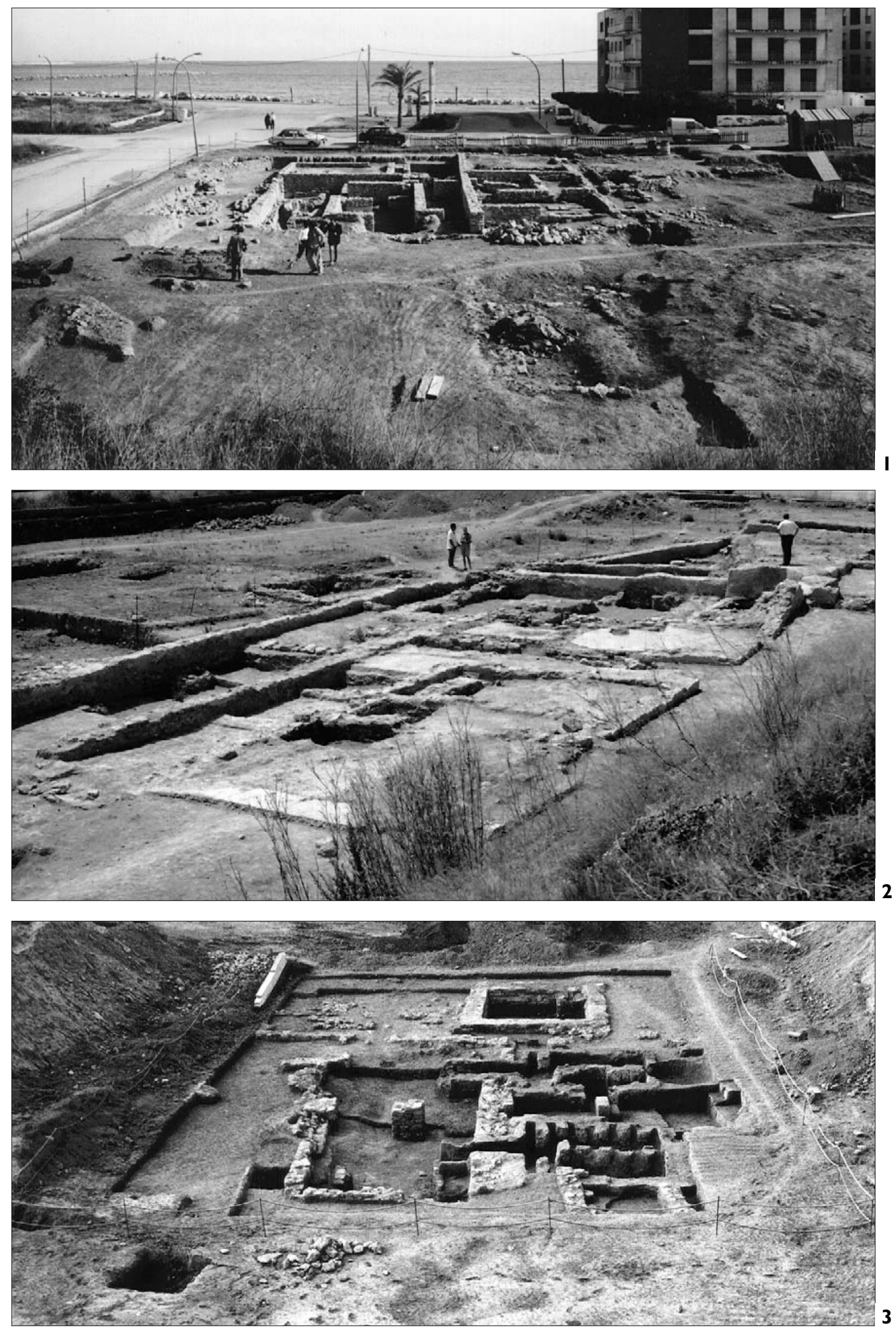

Darró (Vilanova i la Geltrú)

Fig. I. Vista parcial de la excavación del poblado ibérico Fig. 2. Algunas dependencias de la pars rustica de la villa romana descubiertas recientemente Fig. 3. Ruinas del centro productor de ánforas vinarias Pasc. I, Dr. 2 - 4 y Dr. 7 - II 

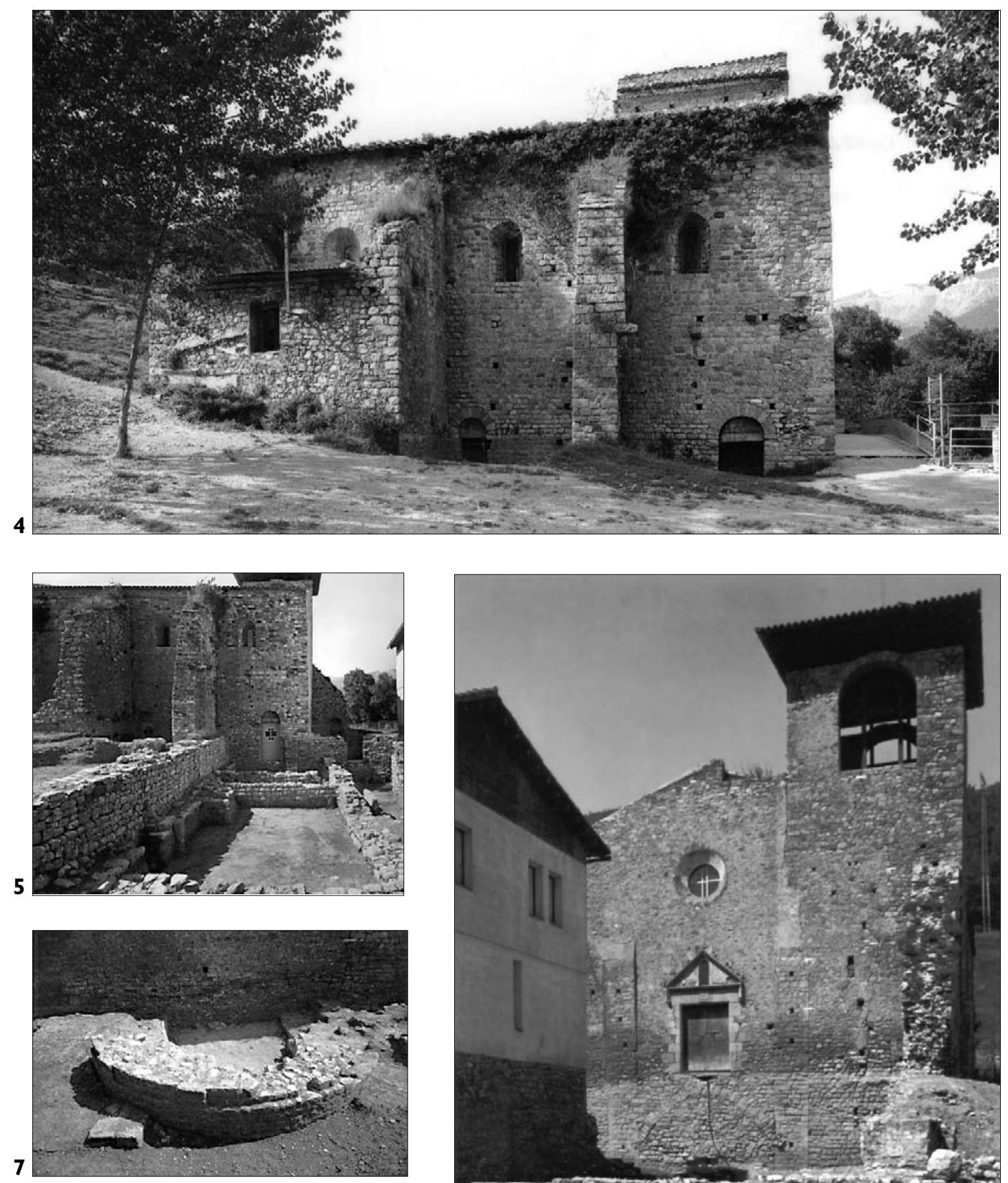

Monasterio de S. Llorenç prop Bagá (Guardiola de Berguedà).

Fig. 4. La fachada meridional de la iglesia en 1984, antes de empezar la excavación. Fig. 5. Entorno meridional de la iglesia en 1988, durante la excavación. Fig. 6. Vista parcial del conjunto desde el nordeste. En primer término las ruinas de la mitad oriental de la basilica, a la izquierda la casa de colonias asentada sobre las dependencias monacales, al fondo la igle-

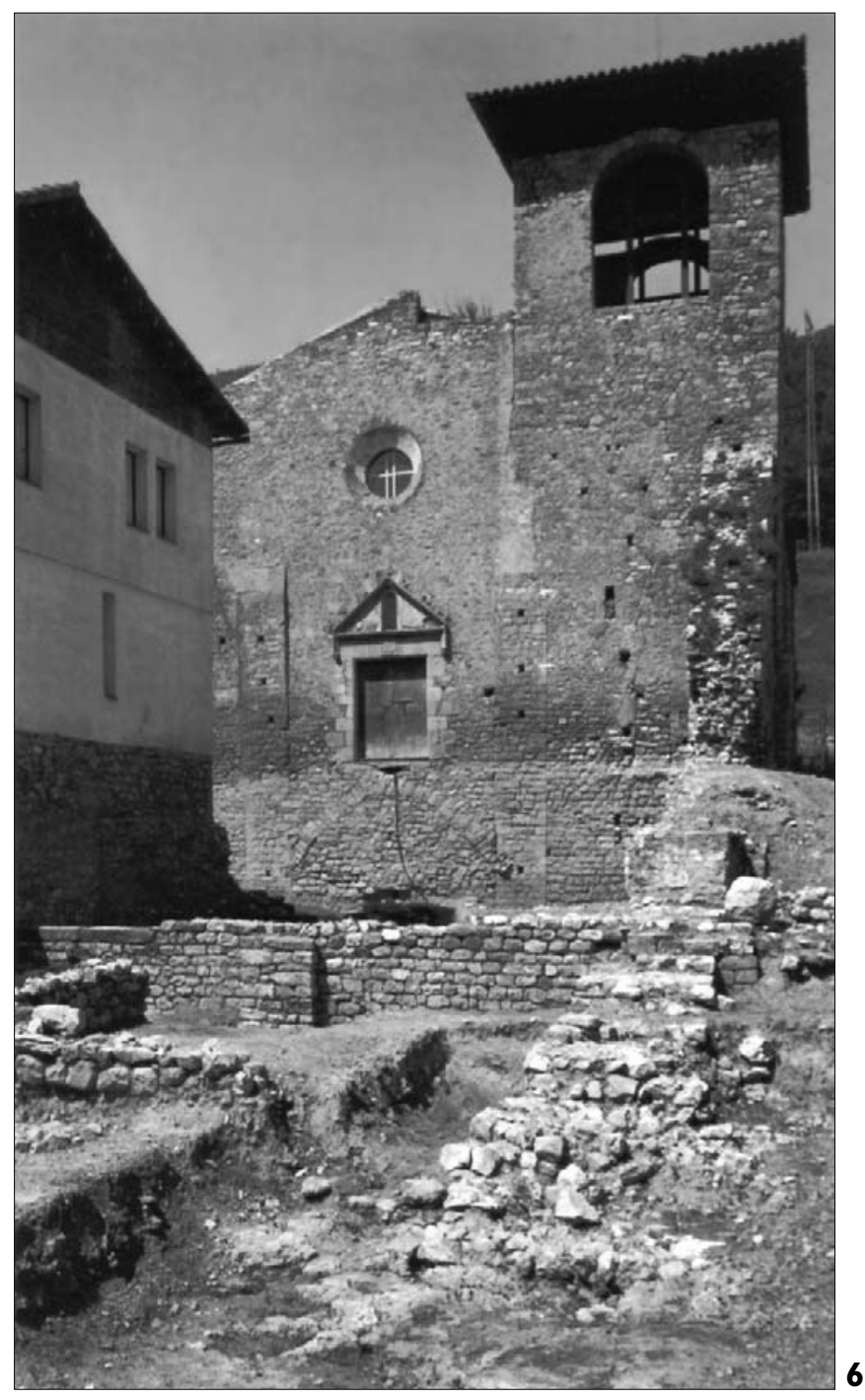
sia actual. Fig. 7. Absidiola occidental del lado sur, descubierta durante la campaña de excavación de 1986 

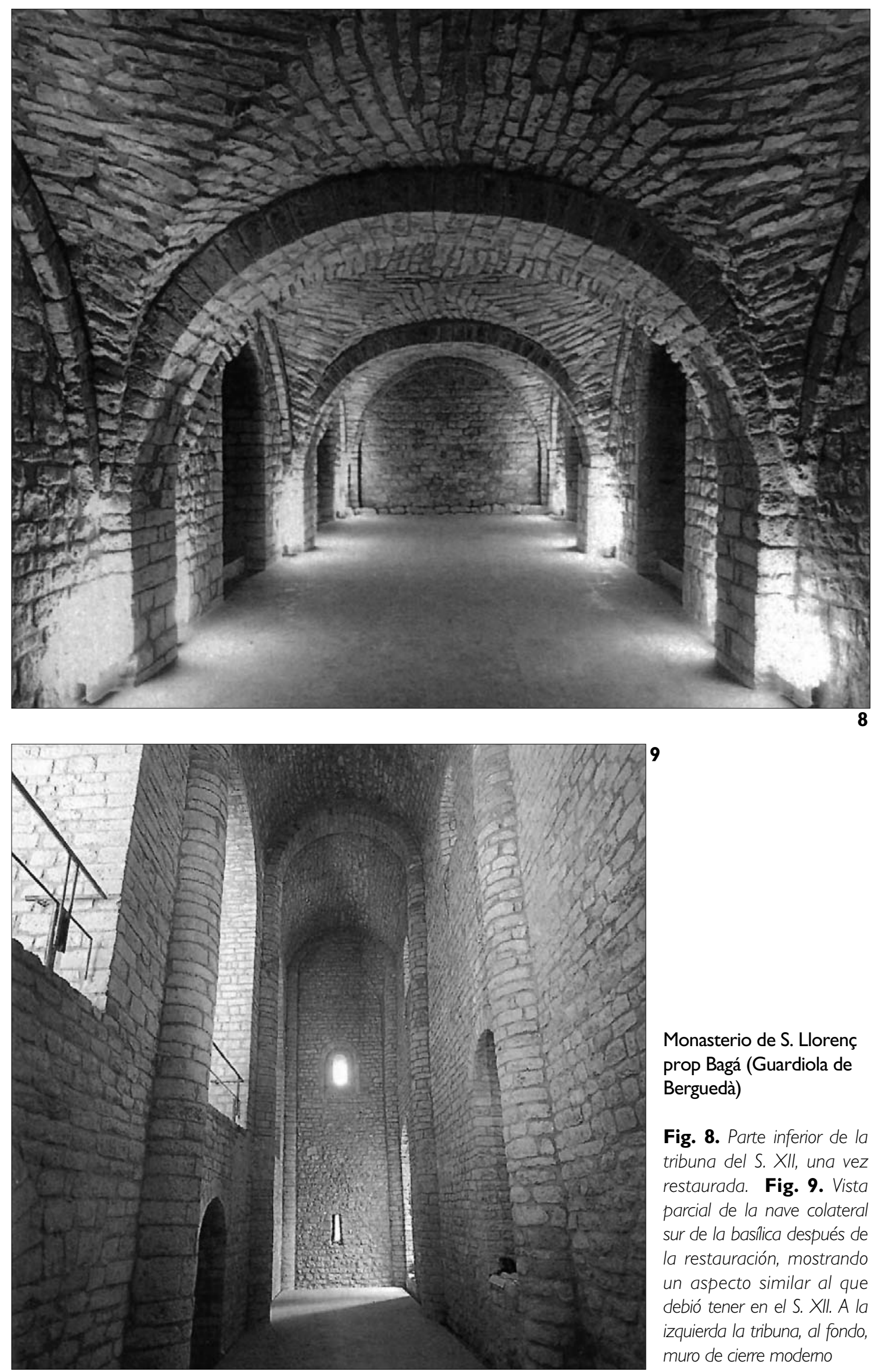

Monasterio de S. Llorenç prop Bagá (Guardiola de Berguedà)

Fig. 8. Parte inferior de la tribuna del S. XII, una vez restaurada. Fig. 9. Vista parcial de la nave colateral sur de la basilica después de la restauración, mostrando un aspecto similar al que debió tener en el S. XII. A la izquierda la tribuna, al fondo, muro de cierre modemo 

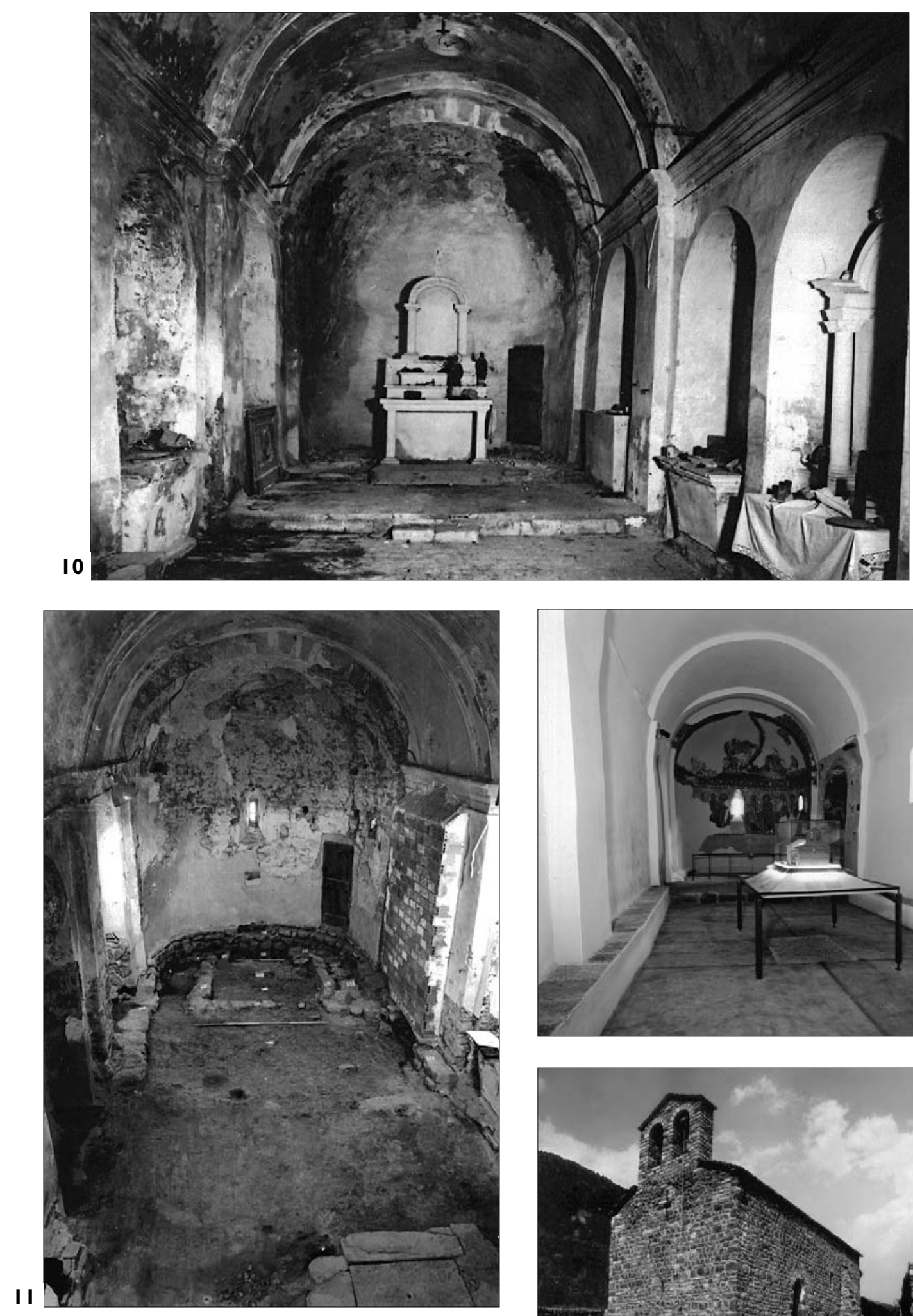

S. Vicent de Rus (Castillar de N'Hug)

Fig. I 0. Interior de la iglesia en 1983, antes de iniciarse la intervención del servicio. Fig. I I. Interior del templo durante la excavación, visto desde poniente.

Fig. I 2. Interior del templo una vez finalizada la restauración. Fig. 13. Exterior de la iglesia después de su excavación, restauración y ordenación
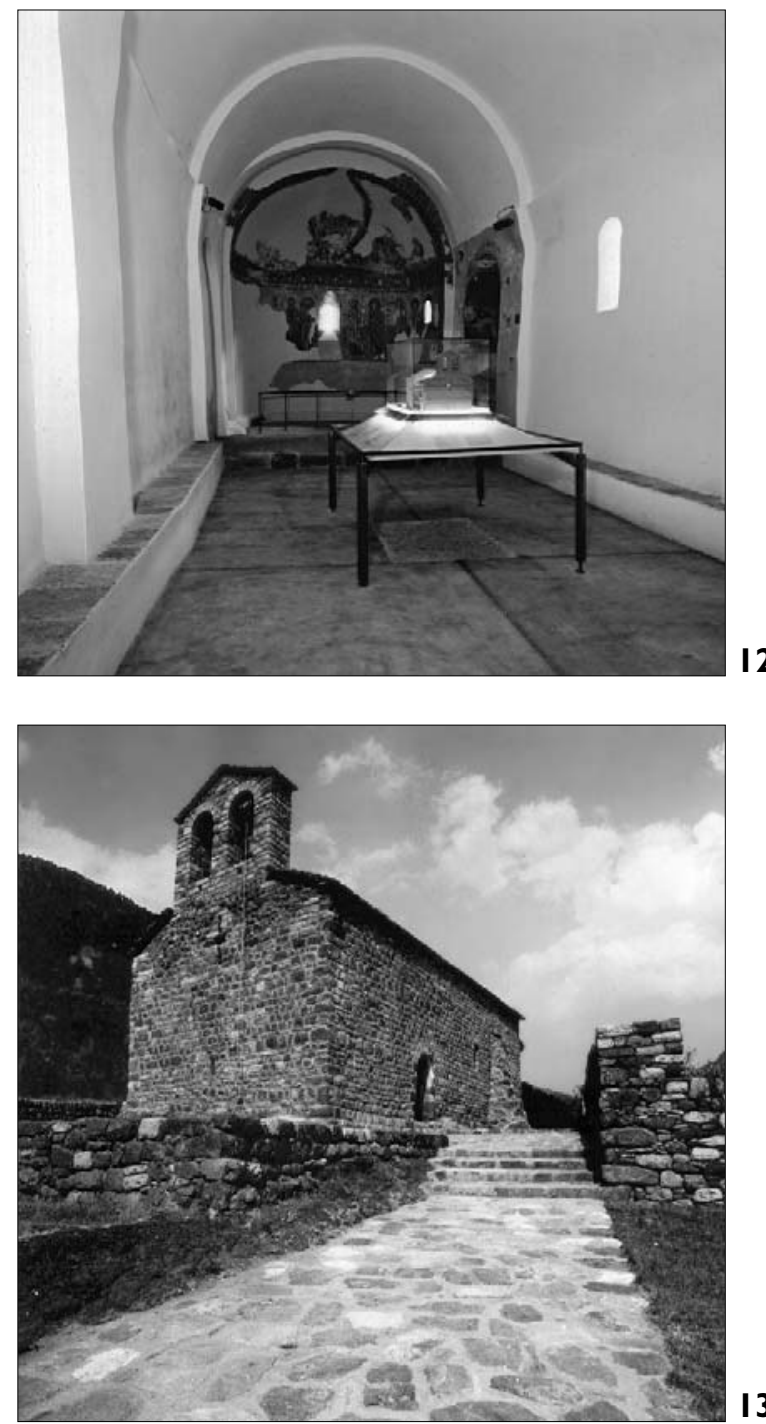